\title{
Effect of Nonmetallic Inclusions on Fatigue Properties of Superelastic Ti-Ni Fine Wire
}

\author{
Fumiyoshi Yamashita ${ }^{1,2, *}$, Yasunori Ide ${ }^{1}$, Suguru Kato ${ }^{3}$, Kyosuke Ueda ${ }^{3}$, \\ Takayuki Narushima ${ }^{3}$, Sumio Kise ${ }^{2}$, Kouji Ishikawa ${ }^{4}$ and Minoru Nishida ${ }^{5}$ (D) \\ 1 Department of Applied Science for Electronics and Materials, Interdisciplinary Graduate School of \\ Engineering Science, Kyushu University, Fukuoka 816-8580, Japan; ide.yasunori.338@s.kyushu-u.ac.jp \\ 2 Technology Development Department, Special Metals Division, Furukawa Techno Material Co., Ltd., \\ Hiratsuka 254-0016, Japan; sumio.kise@furukawaelectric.com \\ 3 Department of Materials Processing, Tohoku University, Sendai 980-8579, Japan; \\ suguru.kato.t5@dc.tohoku.ac.jp (S.K.); ueda@material.tohoku.ac.jp (K.U.); \\ narut@material.tohoku.ac.jp (T.N.) \\ 4 Special Metals Division, Furukawa Techno Material Co., Ltd., Hiratsuka 254-0016, Japan; \\ kouji.moji.ishikawa@furukawaelectric.com \\ 5 Department of Advanced Materials Science and Engineering, Faculty of Engineering Sciences, \\ Kyushu University, Fukuoka 816-8580, Japan; nishida.minoru.355@m.kyushu-u.ac.jp \\ * Correspondence: fumiyoshi.shanxia.yamashita@furukawaelectric.com; Tel.: +81-463-21-7346; \\ Fax: +81-463-21-7069
}

Received: 5 August 2019; Accepted: 6 September 2019; Published: 11 September 2019 updates

\begin{abstract}
This study investigated the effects of the types and length of nonmetallic inclusions on fatigue properties in rotating bending fatigue testing of Ti-Ni alloy fine wire. It was fabricated to include titanium carbides $\mathrm{Ti}(\mathrm{C}, \mathrm{O})$ and titanium oxides $\mathrm{Ti}_{4} \mathrm{Ni}_{2} \mathrm{O}_{x}$ as either single phases or a mixture of both phases as nonmetallic inclusions in Ti-Ni alloy. The fatigue strength of Ti-Ni alloy depended on the number of nonmetallic inclusions of a length of $\geq 2 \mu \mathrm{m}$. Compared with $\mathrm{Ti}(\mathrm{C}, \mathrm{O}), \mathrm{Ti}_{4} \mathrm{Ni}_{2} \mathrm{O}_{x}$ is coarse. It also exhibited a trend of readily forming particles and void assemblies, which are a defect morphology that originates from nonmetallic inclusions and readily act as crack origins of fatigue fractures.
\end{abstract}

Keywords: Ti-Ni alloy; nonmetallic inclusions; fatigue properties; particle and void assembly

\section{Introduction}

Ti-Ni alloy is a functional material that exhibits superelasticity and shapes memory properties. These characteristics are utilized in temperature sensors and actuators, such as in household appliances and electronics. Furthermore, Ti-Ni alloy has excellent corrosion resistance and biocompatibility, and thus is used in medical devices, such as guidewires and stents [1-3]. There are also many studies about Ti-Ni alloy from various aspects, such as the improvement of corrosion resistance [4] and fretting behavior [5]. In particular, stents are medical devices that expand and hold open narrowed areas of hollow anatomical structures, such as blood vessels, and are used for the treatment of circulatory diseases, which have been growing more prevalent in recent years. Metal stents can be made of stainless steel, Co-Cr alloy, or Ti-Ni alloy. Ti-Ni alloy is flexible and is mainly used for cerebral blood vessels and lower limb blood vessels [6].

Stents placed inside the body experience cyclical deformation loads over a long period of time, such as those due to the pulse. Accordingly, there are concerns over fatigue fractures originating from nonmetallic inclusions [2,3,7-11]. In recent years, the demand has grown for ultrafine wire and thin-walled capillary tubes made of Ti-Ni alloy materials for stents. Stent shapes have become more 
sophisticated and the areas where they are placed have expanded. This has led to further concern over problems arising from nonmetallic inclusions. For this reason, the ASTM F2063 series, [6] which is a set of standards for Ti-Ni alloys for medical use, specifies the sizes and area ratios of nonmetallic inclusions, such as titanium carbides $(\mathrm{TiC})$ and titanium oxides $\left(\mathrm{Ti}_{4} \mathrm{Ni}_{2} \mathrm{O}_{x}\right)$. It also specifies the concentrations of the light elements, such as oxygen, carbon, and nitrogen, which are related to the generation of these nonmetallic inclusions. The quantities of nonmetallic inclusions are revised with each version of the standard. Toro et al. [3] observed that nonmetallic inclusions are generated even in Ti-Ni alloy with extremely low concentrations of carbon $(\leq 20 \mathrm{ppm})$ and oxygen $(\leq 50 \mathrm{ppm})$. Furthermore, Rahim et al. [9] reported the results of rotating bending fatigue testing of Ti-Ni wire with a diameter of $0.75 \mathrm{~mm}$ fabricated to contain $\leq 50 \mathrm{ppm}$ of carbon or oxygen. Although the number of nonmetallic inclusions was extremely reduced by lowering the carbon and oxygen contents, the fatigue strength was not improved and was similar to commercial alloys. This formation of nonmetallic inclusions even at extremely low concentrations of oxygen and carbon indicates that the fabrication of Ti-Ni alloy free of nonmetallic inclusions at a commercial scale is difficult in terms of both the production volume and cost.

Although the two types of nonmetallic inclusions [6] known in $\mathrm{Ti}-\mathrm{Ni}$ alloy are $\mathrm{TiC}$ and $\mathrm{Ti}_{4} \mathrm{Ni}_{2} \mathrm{O}_{x}$ as described above, there has been little research on the effect of the types and sizes of these phases on fatigue properties. Ito et al. [12] reported that the types of nonmetallic inclusion phases that form depend on the ratio of carbon and oxygen concentrations (C/O ratio) in Ti-Ni alloy. Although this suggests that the types of nonmetallic inclusion phases can be selectively controlled by adjusting the $\mathrm{C} / \mathrm{O}$ ratio, the details are unclear.

In previous research, the authors found that titanium carbides have a composition where some of the carbon is replaced with oxygen. Titanium carbides were defined as $\operatorname{Ti}(\mathrm{C}, \mathrm{O})$ and the nonmetallic inclusion phases and fatigue properties were investigated in two types of Ti-Ni alloy fine wire formed from single phases of $\mathrm{Ti}(\mathrm{C}, \mathrm{O})$ and $\mathrm{Ti}_{4} \mathrm{Ni}_{2} \mathrm{O}_{x}$. Further, the crack origins of the fatigue fractures were reported [13].

In this research, the authors fabricated Ti-Ni alloy fine wires containing nonmetallic inclusions of single phases or mixed phases of carbides and oxides by varying the C/O ratio in the Ti-Ni alloy. The effect of the types and sizes on the fatigue properties were further investigated.

\section{Experimental Methods}

\subsection{Fabrication of Ti-Ni Alloy Fine Wire Samples Containing Different Nonmetallic Inclusion Phases}

The compositions of the test samples were $\mathrm{Ti}-51.0$ at.\% $\mathrm{Ni}$, which is the composition most commonly used as a superelastic alloy in the medical field. Six samples were fabricated with the concentrations of both carbon and oxygen and varied within a maximum of $500 \mathrm{ppm}$. Ti (99.5\%) and Ni (99.9\%) were used as the raw materials, and the $\mathrm{C} / \mathrm{O}$ ratio was adjusted by the addition of $\mathrm{TiC}$ powder and $\mathrm{TiO}_{2}$ powder to reach the target composition. In this paper, the $\mathrm{C} / \mathrm{O}$ ratio is expressed as a mass ratio. These raw materials were prepared in an arc melting furnace. Melting was performed a total of 6 times in order to further homogenize the alloy, and an ingot of approximate $900 \mathrm{~g}$ was fabricated. The composition of the ingot was found by measuring the carbon content by the combustion-infrared absorption method and measuring the oxygen and nitrogen content by the inert gas fusion-impulse heating method. Table 1 shows the results of the light element analysis for each of the fabricated samples. Furthermore, the carbon and oxygen concentrations of each sample were used to label the samples.

Each of the ingots was hot forged to a diameter of $9.0 \mathrm{~mm}$ at $900{ }^{\circ} \mathrm{C}$. The samples were then wire drawn to a diameter of approximately $160 \mu \mathrm{m}$ by repeatedly alternating between die wire drawing and air annealing at $700{ }^{\circ} \mathrm{C}$. Finally, the samples were constrained to a linear shape by a load applied and held for $30 \mathrm{~s}$ at $500{ }^{\circ} \mathrm{C}$ in an argon atmosphere, and were then cooled. 
The superelastic properties and fatigue properties are affected by the surface condition $[9,10]$. In this experiment, the surfaces of the samples were cleaned by electropolishing in order to suppress the effects of the sample surface condition, such as scratches from wire drawing, on the mechanical properties of the samples and thereby, to clarify the effect of nonmetallic inclusions on fatigue fracture. Electropolishing was performed by using a tubular platinum mesh as the counter electrode (cathode) with the wire samples of diameter $160 \mu \mathrm{m}$ placed in the center. The electrolytic solution was 3M $\mathrm{H}_{2} \mathrm{SO}_{4} / \mathrm{CH}_{3} \mathrm{OH}$ and was kept at $0{ }^{\circ} \mathrm{C}$ by using an ice bath. The solution was stirred using a stirrer while applying $15 \mathrm{~V}$ for $20 \mathrm{~s}$. This reduced the diameter by approximately $10 \mu \mathrm{m}$. The sample surface observations by scanning electron microscopy (SEM, ULTRA55, Carl Zeiss, Germany) confirmed that the surfaces of all samples were smooth and free of wire drawing scratches. Thus, the wire samples with a diameter of approximately $150 \mu \mathrm{m}$ prepared by the above process were used for tensile testing and rotating bending fatigue testing.

The austenite finish temperature $A_{f}$ of each sample (rightmost column, Table 1) was measured in accordance with ASTM F 2082-06 [14] for measuring the dynamic reverse transformation temperature.

Table 1. Chemical compositions (mass $\%$ ) and $A_{f}$ temperature of Ti-Ni alloys.

\begin{tabular}{cccccc}
\hline Notation & $\mathbf{C}$ & $\mathbf{O}$ & $\mathbf{N}$ & $\mathbf{C} / \mathbf{O}$ & $\boldsymbol{A}_{\boldsymbol{f}},{ }^{\circ} \mathbf{C}$ \\
\hline C30O100 & 0.0033 & 0.0118 & 0.0007 & 0.28 & 32.1 \\
C100O100 & 0.0108 & 0.0108 & 0.0009 & 1.00 & 31.9 \\
C200O100 & 0.0189 & 0.0116 & 0.0013 & 1.63 & 29.5 \\
C200O400 & 0.0212 & 0.0399 & 0.0010 & 0.53 & 32.8 \\
C300O300 & 0.0297 & 0.0249 & 0.0010 & 1.19 & 28.5 \\
C400O200 & 0.0391 & 0.0187 & 0.0016 & 2.09 & 29.2 \\
\hline
\end{tabular}

\subsection{Identification and Particle Analysis of Nonmetallic Inclusions}

To confirm the nonmetallic inclusion phases in each sample, electrolytic extraction was performed for $60 \mathrm{~min}$ at $4 \mathrm{~V}$ by using selective potentiostatic etching by electrolytic dissolution (SPEED). The wire samples of a diameter of approximately $150 \mu \mathrm{m}$ were immersed in electrolytic solution containing a mixture of $10 \%$ acetyl acetone, $1 \%$ tetramethylammonium chloride, and methyl alcohol. The solution containing the dissolved samples was suction filtered over a membrane filter, and after separating the nonmetallic inclusions as residue, they were identified by $x$-ray diffraction (XRD, MiniFlex600, Rigaku, Japan) with $\mathrm{Cu} \mathrm{K} \alpha$ radiation.

To study the number and particle size distribution of the nonmetallic inclusion phases in each sample, the wire samples of diameter approximately $150 \mu \mathrm{m}$ were embedded in resin in the wire drawing direction. They were then polished to a mirror surface by wet polishing using SiC (\#320) and $6 \mu \mathrm{m}$ and $3 \mu \mathrm{m}$ diamond paste and buff polishing using colloidal silica. The compositions of the nonmetallic inclusions in the fabricated samples were analyzed by SEM with an energy-dispersive $x$-ray spectroscopy (EDS, X-Max ${ }^{\mathrm{N}}$, Oxford Instruments, Abingdon, United Kingdom) attachment. Furthermore, EDS analysis was performed on each detected particle by using the particle analysis software INCA Feature (Oxford Instruments, Abingdon, United Kingdom) to separately identify $\mathrm{Ti}(\mathrm{C}, \mathrm{O})$ and $\mathrm{Ti}_{4} \mathrm{Ni}_{2} \mathrm{O}_{x}$ and collect information about each particle. The particle analysis conditions were set to count nonmetallic inclusions with a major axis length parallel to the wire drawing direction (hereinafter, the length) of $\geq 0.2 \mu \mathrm{m}$ as detected within the surface area of 4 fields of view $\left(5.0 \times 10^{4} \mu \mathrm{m}^{2}\right.$ in total) at a magnification of 1000 times by SEM.

\subsection{Tensile Testing}

Tensile testing was performed using the wire samples described in Section 2.1 in a constant temperature bath at $37{ }^{\circ} \mathrm{C}$ with a distance between the marks of $40 \mathrm{~mm}$ at a strain rate of $0.00017 \mathrm{~s}^{-1}$ by applying and removing loading up to a tensile strain of $6 \%$. The superelastic properties were confirmed, and Young's modulus was estimated from the gradient in the elastic area. 


\subsection{Rotating Bending Fatigue Testing}

A dual drive rotating bending fatigue tester was used (Figure 1). The strain amplitude $\varepsilon_{a}$ and maximum bending stress $\sigma$ applied to the sample were calculated from Equations (1) and (2), respectively, and were controlled by changing the distance between the centerline of the two axles $D$ [15]. The parameters $d$ and $E$ in Equations (1) and (2) are the diameter and Young's modulus of the samples, respectively.

$$
\begin{gathered}
\varepsilon_{a}=d / D \times 100 \\
\sigma=E \times d / D
\end{gathered}
$$

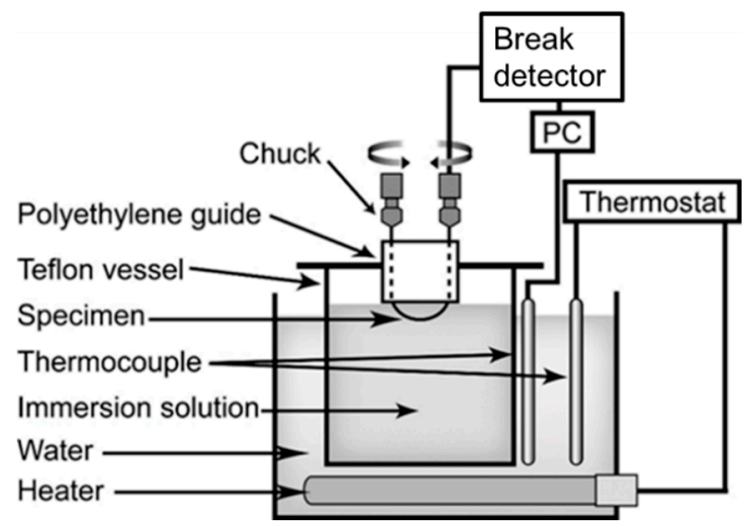

Figure 1. Schematic illustration of the rotating bending fatigue test setup.

The fatigue tests were conducted in a testing environment with the bent part of the sample immersed in a bath of Hanks' solution $(\mathrm{pH}=7.4) \mathrm{kept}$ at $37^{\circ} \mathrm{C}$ to simulate the temperature inside the body. The number of fractures was determined by monitoring the voltage between the chucks. The rotation speed was set to $1000 \mathrm{rpm}$ and the maximum number of test revolutions was set to $10^{7}$.

The fracture surface after the fatigue test was observed by SEM, and the composition of nonmetallic inclusions present at crack origins was analyzed by EDS.

\subsection{Measurement of Nonmetallic Inclusions and Surrounding Defects}

Furthermore, the lengths of the nonmetallic inclusions observed in the surface of the wire samples electropolished as described in Section 2.1, as well as the particle and void assemblies (PVAs) and the fully embedded (FE) morphology where there are no voids around the nonmetallic inclusions, were measured by SEM.

\section{Results and Discussion}

\subsection{Nonmetallic Inclusion Phases and Particle Size Distribution in Each Sample}

Figure 2 shows the SEM backscattered electron (BSE) images of the side surfaces of each sample. As can be seen from the low-magnification images and high-magnification insets, two types of particles-one characterized by a slightly darker contrast and another by a much darker contrast compared with the Ti-Ni matrix-were observed in all samples. The difference between these contrasts is thought to depend on the concentration of $\mathrm{Ni}$, which has the highest atomic number among the constituent elements. Furthermore, from the results of the EDS analysis and XRD described below, the particles with slightly darker contrast were identified as $\mathrm{Ti}_{4} \mathrm{Ni}_{2} \mathrm{O}_{x}$ and the ones with much darker contrast were identified as $\mathrm{Ti}(\mathrm{C}, \mathrm{O})$. A trend was observed where the amount of nonmetallic inclusions generated increased in proportion to the sum of the concentrations of oxygen and carbon as described later. For a given sum, there was a trend for a larger number of coarse $\mathrm{Ti}_{4} \mathrm{Ni}_{2} \mathrm{O}_{x}$ particles to appear as 
the oxygen concentration increased (Figure 2d). However, in samples where the carbon concentration was high, the $\operatorname{Ti}(\mathrm{C}, \mathrm{O})$ was distributed toward finer particles (Figure 2f).

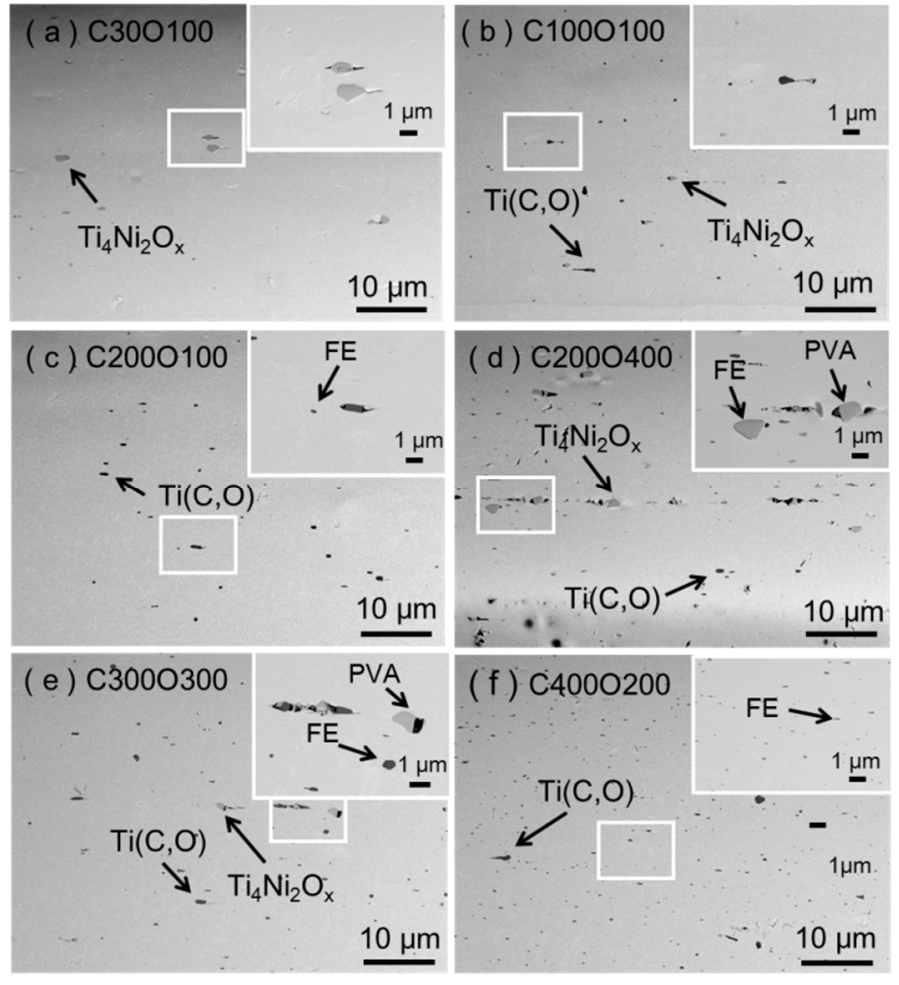

Figure 2. Scanning electron microscopy (SEM)-Backscattered electron (BSE) images of wire surfaces after electropolishing. (a) C30O100, (b) C100O100, (c) C200O100, (d) C200O400, (e) C300O300 and (f) $\mathrm{C} 400 \mathrm{O} 200$. Insets in the upper right show enlarged micrographs taken from the framed area in each low-magnification images.

Figure 3 show the results of the phase identification by XRD on nonmetallic inclusions extracted by the SPEED method. When the $\mathrm{C} / \mathrm{O}$ ratio was low $(\mathrm{C} / \mathrm{O}<0.5)$, the single-phase $\mathrm{Ti}_{4} \mathrm{Ni}_{2} \mathrm{O}_{x}$ was present. When $0.5<\mathrm{C} / \mathrm{O}<1.5$, there was a mixture of $\mathrm{Ti}_{4} \mathrm{Ni}_{2} \mathrm{O}_{x}$ and $\mathrm{Ti}(\mathrm{C}, \mathrm{O})$ phases with the amount of $\mathrm{Ti}(\mathrm{C}, \mathrm{O})$ increasing as the $\mathrm{C} / \mathrm{O}$ ratio increased. At $\mathrm{C} / \mathrm{O}>1.5$, the single-phase $\mathrm{Ti}(\mathrm{C}, \mathrm{O})$ was present. The above results suggest that the phases of the nonmetallic inclusions can be controlled by adjusting the $\mathrm{C} / \mathrm{O}$ ratio during dissolution.
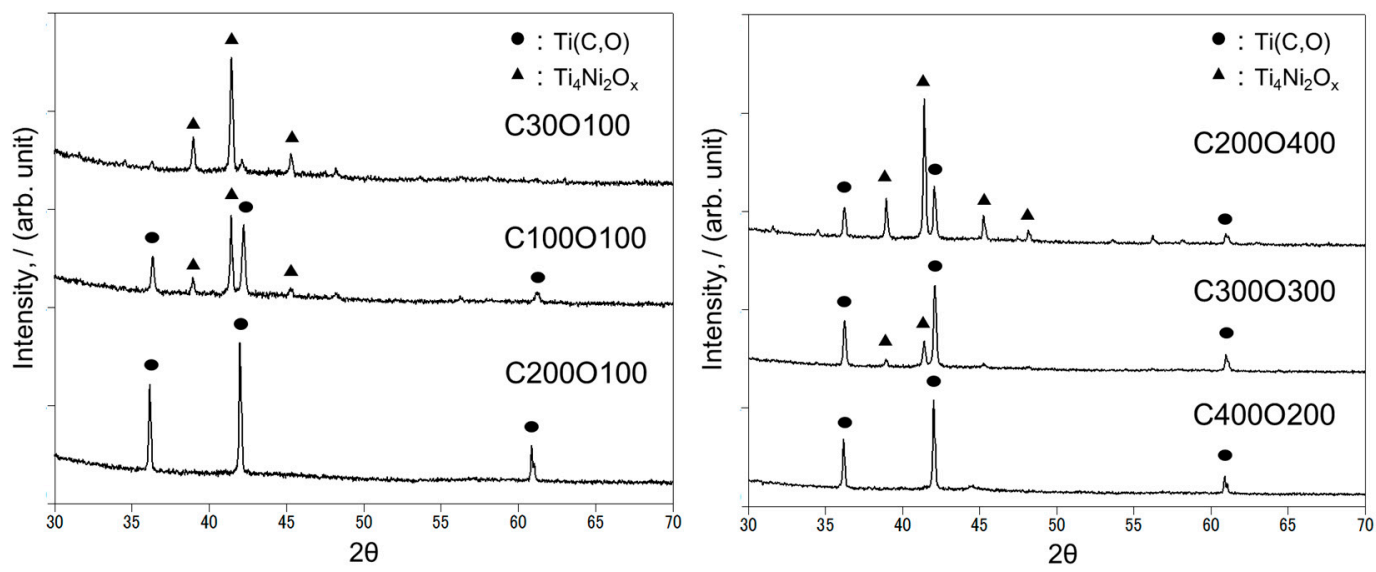

Figure 3. X-ray diffraction (XRD) patterns of nonmetallic inclusions extracted from six wire samples by selective potentiostatic etching by electrolytic dissolution (SPEED) technique. 
It was also found that when $\mathrm{C} / \mathrm{O}>1.5$, the state of the single-phase $\mathrm{Ti}(\mathrm{C}, \mathrm{O})$ was maintained even after hot forging and wire drawing. Note that the TiC peaks in Figure 3 are slightly shifted to a higher angle compared with the TiC data (00-32-1383) from the International Centre for Diffraction Data. This is because the $\mathrm{TiC}$ in the samples has a composition where some of the carbon has been replaced with oxygen, and the lattice constant is slightly smaller than $\mathrm{TiC}[16,17]$. Thus, the titanium carbides are referred to as $\mathrm{Ti}(\mathrm{C}, \mathrm{O})$ in this paper.

Figure $4 \mathrm{a}-\mathrm{f}$ shows the results of the particle analysis in each sample. The number of coarse nonmetallic inclusions with a length of $\geq 2 \mu \mathrm{m}$ increases as the $\mathrm{C} / \mathrm{O}$ ratio decreases, and the number of coarse nonmetallic inclusions with a length of $\geq 2 \mu \mathrm{m}$ decreases as the $\mathrm{C} / \mathrm{O}$ ratio increases. Furthermore, nonmetallic inclusions with a length of $\geq 2 \mu \mathrm{m}$ were mainly the $\mathrm{Ti}_{4} \mathrm{Ni}_{2} \mathrm{O}_{x}$, and $\mathrm{Ti}(\mathrm{C}, \mathrm{O})$ inclusions with a length of $>10 \mu \mathrm{m}$ which were not observed in any of the samples. These results are consistent with the SEM observations shown in Figure 2. Furthermore, there was a tendency for the number of nonmetallic inclusions to decrease as the sum of the carbon and oxygen concentrations decreased, which is consistent with the results in the literature [3,9].
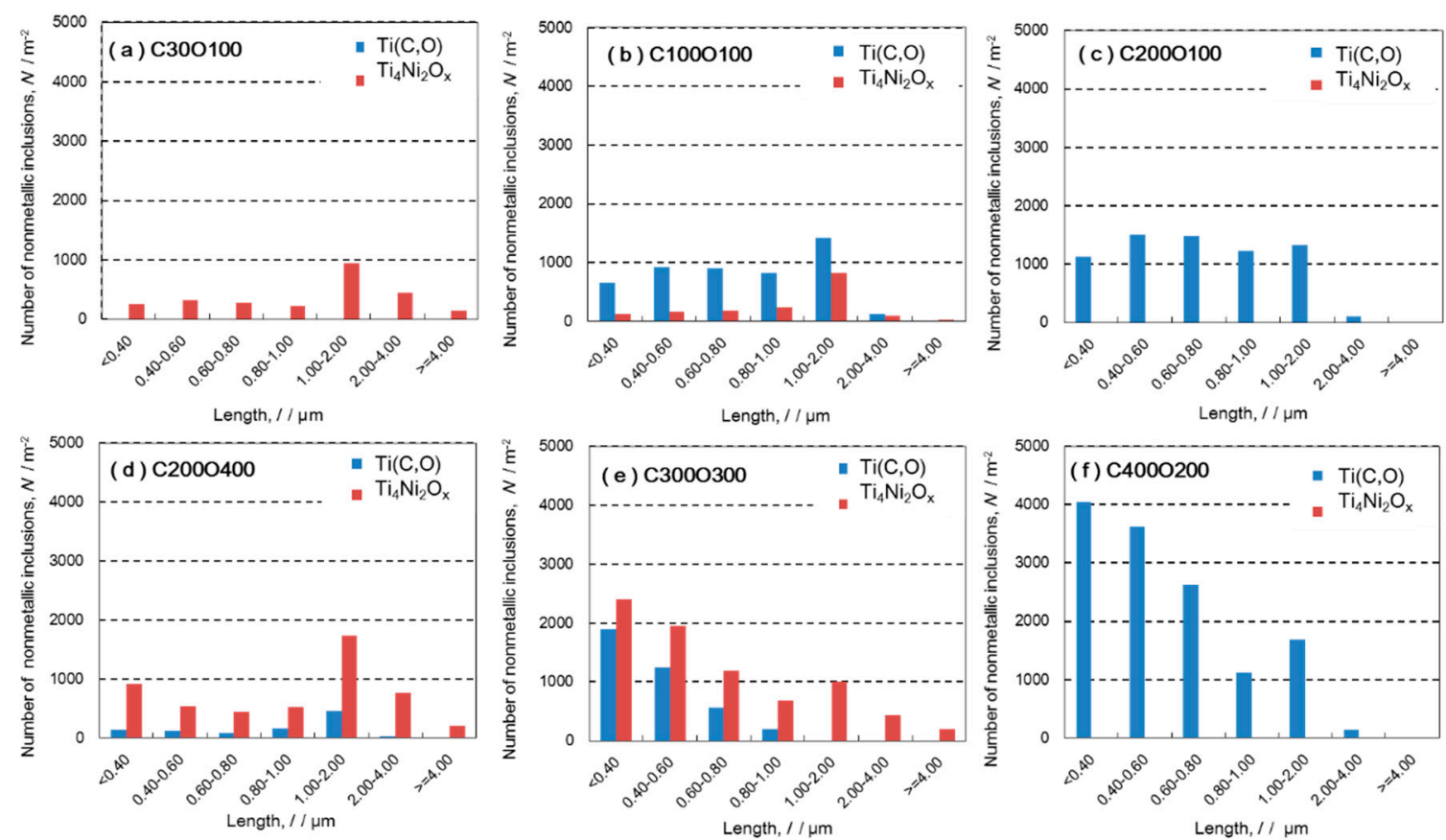

Figure 4. Analysis of nonmetallic inclusions by phase and distribution of length parallel to the wire drawing direction. (a) C30O100, (b) C100O100, (c) C200O100, (d) C200O400, (e) C300O300, and (f) C400O200.

From the above results, the relationship between the $\mathrm{C} / \mathrm{O}$ ratio and the nonmetallic inclusion phase in the 6 samples fabricated in this research showed good agreement with a report by Ito et al. [12].

\subsection{Effect of Types and Length of Nonmetallic Inclusion Phases on Fatigue Strength}

Figure 5 shows the results of the tensile test for each sample. Substantial superelastic properties at $37^{\circ} \mathrm{C}$ were found in all cases. Table 2 shows Young's modulus as estimated from the gradient in the elastic region.

Figure 6 shows the SN curves (stress versus the number of cycles to failure) obtained from the rotating bending fatigue tests. The right-pointing arrows in the figure indicate the samples that had not failed by the maximum number of revolutions $\left(10^{7}\right)$ used in this experiment. All of the SN curves exhibited a trend with a steep gradient in the low cycle number region. The gradient changed at approximately $10^{4}$ revolutions, with the rate change decreasing and the curves converging to an almost constant value in the high cycle number region. The stress at this point was taken as the fatigue 
strength. The samples with a $\mathrm{C} / \mathrm{O}$ ratio of $>1.5$ exhibited higher fatigue strength compared to the samples with a $\mathrm{C} / \mathrm{O}$ ratio of $<1.5$.

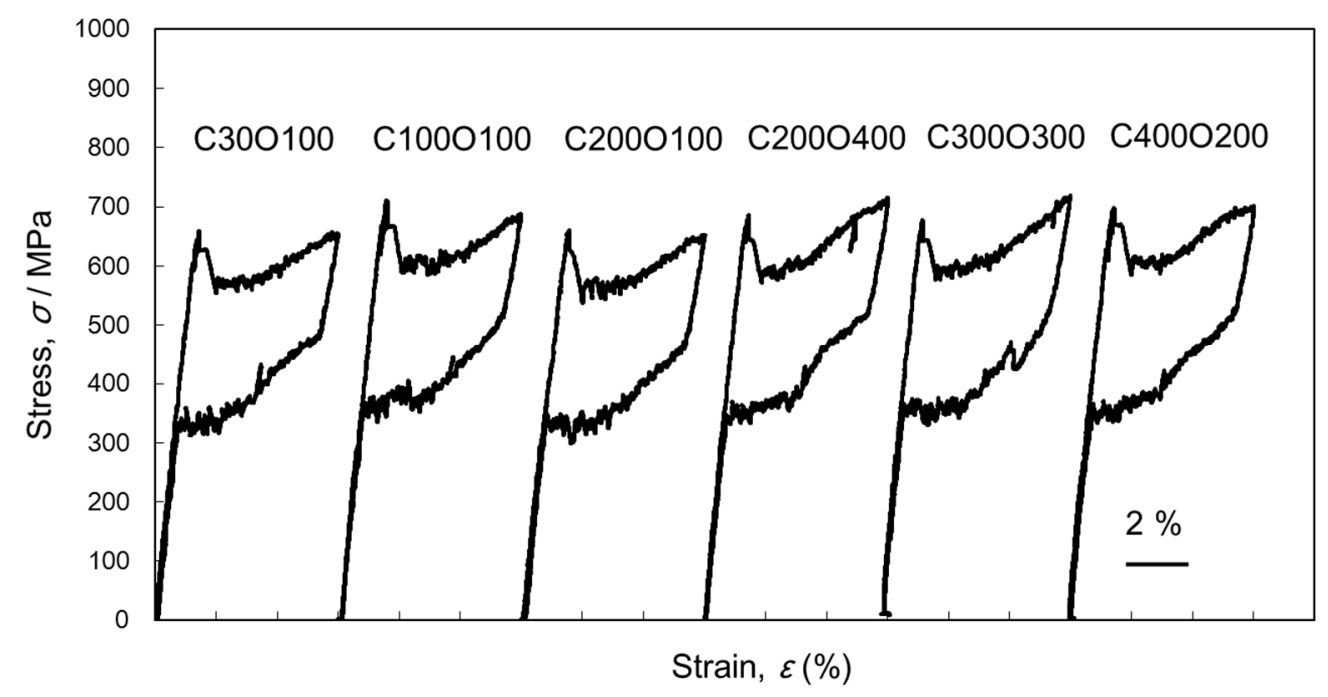

Figure 5. Stress-strain curves of Ti-Ni wires at $37^{\circ} \mathrm{C}$.

Table 2. Young's modulus of Ti-Ni wires.

\begin{tabular}{cc}
\hline Ti-Ni Wire & Young's Modulus, GPa \\
\hline C30O100 & 48.27 \\
C100O100 & 49.35 \\
C200O100 & 47.31 \\
C200O400 & 52.30 \\
C300O300 & 50.38 \\
C400O200 & 47.05 \\
\hline
\end{tabular}

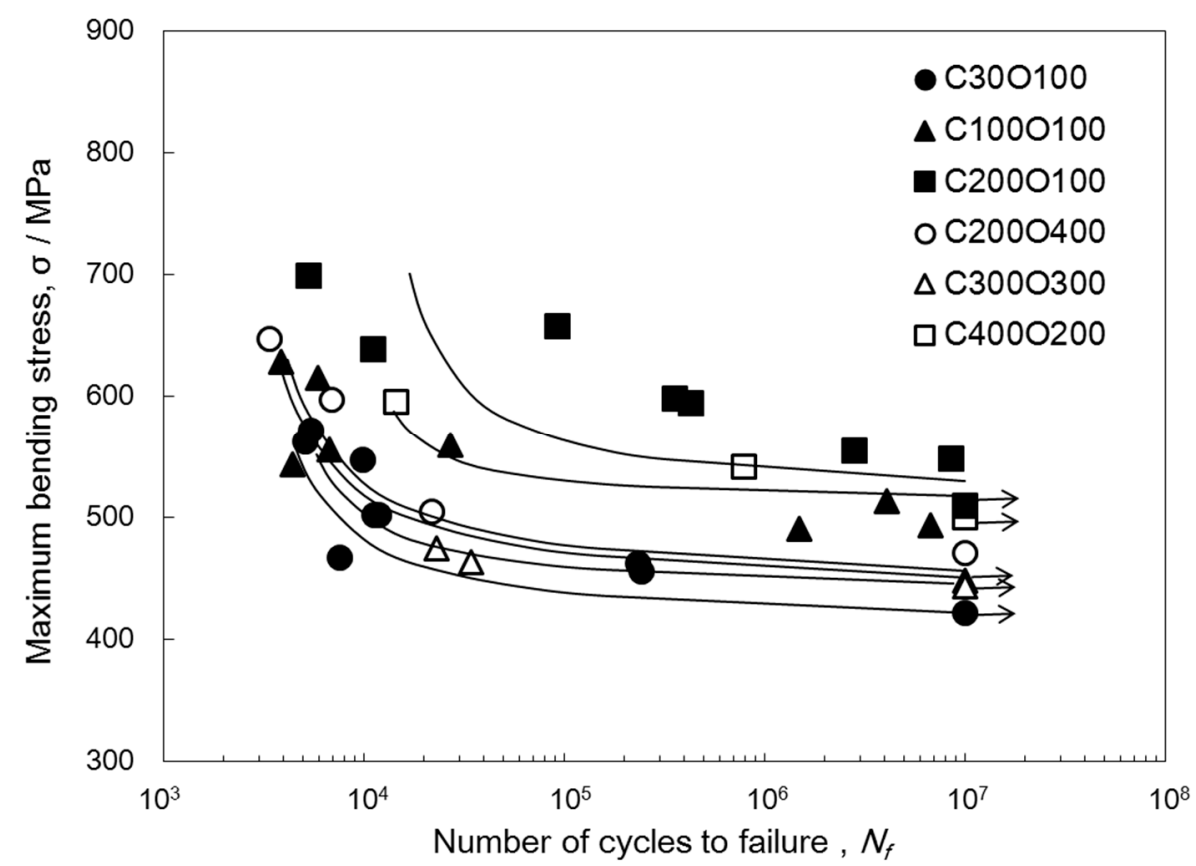

Figure 6. Fatigue curves of $\mathrm{C} 30 \mathrm{O} 100, \mathrm{C} 100 \mathrm{O} 100, \mathrm{C} 200 \mathrm{O} 100, \mathrm{C} 200 \mathrm{O} 400, \mathrm{C} 300 \mathrm{O} 300$, and $\mathrm{C} 400 \mathrm{O} 200$ wires in rotating bending fatigue tests in Hanks' solution kept at $37^{\circ} \mathrm{C}$. Arrows indicate no failure after $10^{7}$ cycles in the tests. 
Figure 7 shows the SEM secondary electron (SE) images of a pair of fatigue fracture surfaces from a sample. A nonmetallic inclusion is present on one of the fracture surfaces (Figure 7a) and a void can be seen on the other (Figure 7b). The nonmetallic inclusion in Figure 7a was identified as $\mathrm{Ti}_{4} \mathrm{Ni}_{2} \mathrm{O}_{x}$ phase from the EDS analysis results in Table 3. When the fracture surfaces were similarly observed, the measurement results for the length of nonmetallic inclusions at the crack origins showed that many were $\geq 2 \mu \mathrm{m}$.
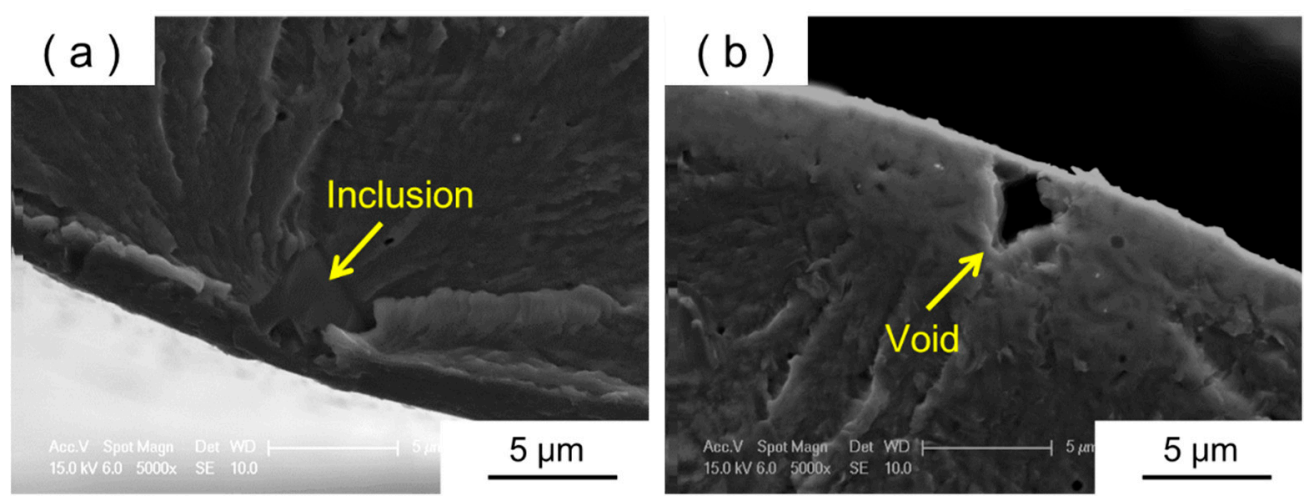

Figure 7. SEM-SE images of a pair of fracture surfaces of $\mathrm{C} 300 \mathrm{O} 300$ wire after fatigue test. (a) Fracture surface containing $\mathrm{Ti}_{4} \mathrm{Ni}_{2} \mathrm{O}_{x}$ inclusion acted as crack initiation site. (b) Counter part of fracture surface containing void corresponding to the trace of inclusion in (a).

Figure 8 shows the relationship between the number of nonmetallic inclusions with a length of $\geq 2 \mu \mathrm{m}$ as estimated from the results of the particle analysis shown in Figure 4 and the fatigue strength. It was found that the fatigue strength decreased as the number of nonmetallic inclusions of a length of $\geq 2 \mu \mathrm{m}$ increased. This reflects the tendency for coarse nonmetallic inclusions of a length of $\geq 2 \mu \mathrm{m}$ to readily act as crack origins. The SEM observations of fatigue fracture surfaces revealed that nonmetallic inclusions of a length of $\geq 2 \mu \mathrm{m}$ acted as crack origins. There were lots of $\mathrm{Ti}_{4} \mathrm{Ni}_{2} \mathrm{O}_{x}$ particles of a length of $\geq 2 \mu \mathrm{m}$ in the C30O100 samples. On the other hand, there were a few $\operatorname{Ti}(\mathrm{C}, \mathrm{O})$ particles of a length of $\geq 2 \mu \mathrm{m}$ in the $\mathrm{C} 200 \mathrm{O} 100$ and $\mathrm{C} 400 \mathrm{O} 200$ samples. In addition, in the C100O100, C300O300, and C200O400 samples, which had a mixture of $\mathrm{Ti}(\mathrm{C}, \mathrm{O})$ and $\mathrm{Ti}_{4} \mathrm{Ni}_{2} \mathrm{O}_{x}$ phases, the $\mathrm{Ti}_{4} \mathrm{Ni}_{2} \mathrm{O}_{x}$ was coarser than $\mathrm{Ti}(\mathrm{C}, \mathrm{O})$ and selectively acted as the crack origin of fatigue fractures.

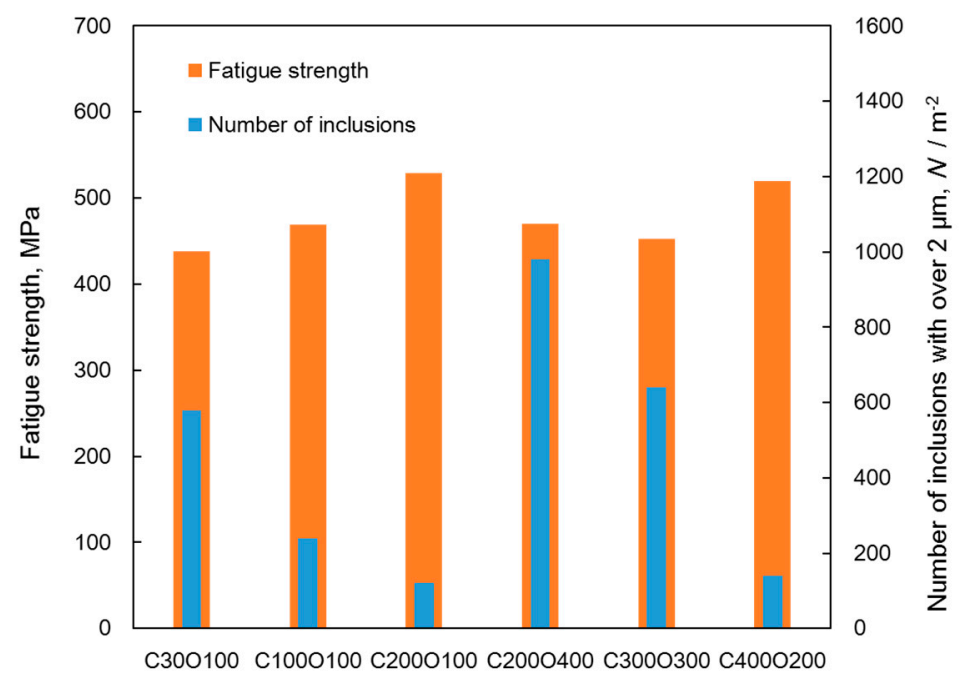

Figure 8. Relation between the fatigue strength and the number of nonmetallic inclusions of $>2 \mu \mathrm{m}$ in length parallel to the wire drawing direction. 
Table 3. Energy-dispersive X-ray spectroscopy (EDS) analysis of nonmetallic inclusions at the crack origins in a fatigue fracture surface of $\mathrm{C} 300 \mathrm{O} 300$ wire.

\begin{tabular}{cc}
\hline Element & Content (at.\%) \\
\hline $\mathrm{Ti}$ & 52.42 \\
$\mathrm{Ni}$ & 27.15 \\
$\mathrm{O}$ & 16.28 \\
$\mathrm{C}$ & 4.15 \\
\hline
\end{tabular}

\subsection{Relationship between PVAs and Fatigue Strength}

Figure 9 shows a surface SEM-BSE image of a sample where failure did not occur after $10^{7}$ revolutions in the fatigue tests. In the tests, the cracks propagated from the interfaces between $\mathrm{Ti}_{4} \mathrm{Ni}_{2} \mathrm{O}_{x}$, which has PVA morphology, and the surrounding void based on $\mathrm{Ti}_{4} \mathrm{Ni}_{2} \mathrm{O}_{x}$ and $\mathrm{Ti}(\mathrm{C}, \mathrm{O})$ identified in Figure 2. However, the occurrence of cracks from $\mathrm{Ti}(\mathrm{C}, \mathrm{O})$, which has an FE morphology, was not observed. Therefore, many of the pairs of fatigue fracture surfaces exhibited the morphology shown in Figure 7. This suggests that the cracks occurred at the interfaces between the nonmetallic inclusions and the voids as indicated by the arrow in Figure 9, leading to failure. Rahim et al. [7] also reported the adverse effect of the PVA morphology comprising of a nonmetallic inclusion and void as shown in Figure 9.

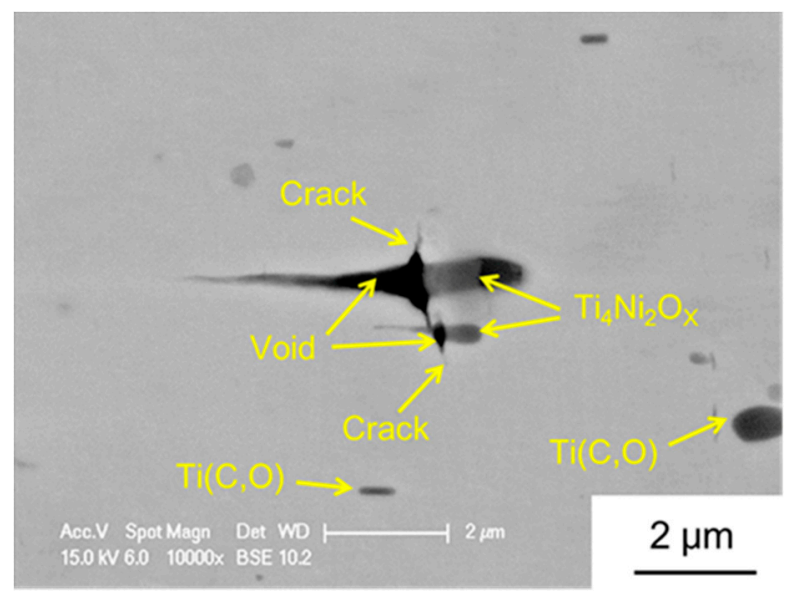

Figure 9. SEM-BSE image of $\mathrm{C} 200 \mathrm{O} 400$ wire surface without failure after $10^{7}$ cycles in the fatigue tests.

The PVA morphology and FE morphology shown in Figure 2d,e, respectively, were observed in the surface of each sample before fatigue testing where electropolishing was performed. Abundant $\mathrm{Ti}(\mathrm{C}, \mathrm{O})$ with an FE morphology was observed, particularly in Figure $2 \mathrm{c}, \mathrm{f}$ where there are many fine nonmetallic inclusions. To examine the effect of the nonmetallic inclusion phase on the formation ratio of PVA morphology to FE morphology, the following were compared after electropolishing: C200O100 and C400O200, which are single-phase $\mathrm{Ti}(\mathrm{C}, \mathrm{O}) ; \mathrm{C} 30 \mathrm{O} 100$, which is single-phase $\mathrm{Ti}_{4} \mathrm{Ni}_{2} \mathrm{O}_{x}$, and $\mathrm{Ti}_{4} \mathrm{Ni}_{2} \mathrm{O}_{x}$ selectively choosing from C200O400, which has $\mathrm{Ti}_{4} \mathrm{Ni}_{2} \mathrm{O}_{x}$ as the main phase. The number of PVAs and FE inclusions per unit area in each of these samples was measured and calculated from the SEM observation, and the PVA fraction was found using the following equation:

$$
f_{\mathrm{PVA}}=N_{\mathrm{PVA}} /\left(N_{\mathrm{PVA}}+N_{\mathrm{FE}}\right)
$$

where $f_{\text {PVA }}$ is the PVA fraction, $N_{\text {PVA }}$ is the number of PVA inclusions in a field of view per $\mathrm{mm}^{2}$, and $N_{\mathrm{FE}}$ is the number of FE inclusions in field of view per $\mathrm{mm}^{2}$. The results are shown in Figure 10. A comparison of the samples with single-phase $\mathrm{Ti}(\mathrm{C}, \mathrm{O})$, the samples with single-phase $\mathrm{Ti}_{4} \mathrm{Ni}_{2} \mathrm{O}_{x}$, 
and the samples with $\mathrm{Ti}_{4} \mathrm{Ni}_{2} \mathrm{O}_{x}$ as the main phase revealed a trend for $\mathrm{Ti}_{4} \mathrm{Ni}_{2} \mathrm{O}_{x}$ to have more nonmetallic inclusions with the PVA morphology.

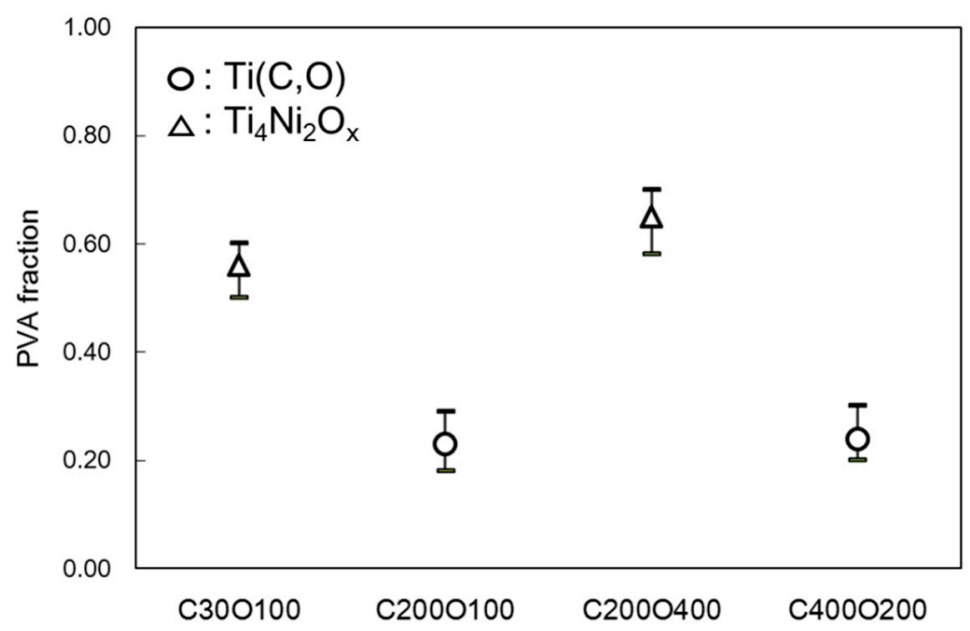

Figure 10. The relationship between particle and void assemblies (PVA) fraction and inclusion phase. The plots show the mean of 5 measurements and the error bar.

From these results, the $\mathrm{Ti}_{4} \mathrm{Ni}_{2} \mathrm{O}_{x}$ that forms in superelastic Ti-Ni fine wire exhibits a tendency of not only having coarser size compared with $\mathrm{Ti}(\mathrm{C}, \mathrm{O})$, but also readily forming PVA. Thus, $\mathrm{Ti}_{4} \mathrm{Ni}_{2} \mathrm{O}_{x}$ appears to selectively serve as a crack origin due to these synergistic effects and is prone to degradation of fatigue properties.

\section{Conclusions}

This study examined the effect of nonmetallic inclusions on the fatigue properties of superelastic Ti-Ni fine wire and obtained the following results.

(1) Nonmetallic inclusions in fine wire as the final product shape can be controlled to single-phase $\mathrm{Ti}(\mathrm{C}, \mathrm{O})$, single-phase $\mathrm{Ti}_{4} \mathrm{Ni}_{2} \mathrm{O}_{x}$, or a mixture of both phases by adjusting the concentrations of carbon and oxygen during dissolution.

(2) Ti-Ni alloy fine wire samples containing nonmetallic inclusions of only single-phase $\operatorname{Ti}(\mathrm{C}, \mathrm{O})$ exhibited higher fatigue strength than the samples containing single-phase $\mathrm{Ti}_{4} \mathrm{Ni}_{2} \mathrm{O}_{x}$ or mixed phases.

(3) The fatigue strength of Ti-Ni alloy depended on the number of nonmetallic inclusions of a length of $\geq 2 \mu \mathrm{m}$.

(4) Among the crack origins of fatigue fractures, many were observed to have originated from nonmetallic inclusions with the PVA morphology from the pairs of fatigue fracture surfaces.

(5) When each of the samples before fatigue testing was observed, there was a tendency for ratios of the PVA morphology to be higher in the $\mathrm{Ti}_{4} \mathrm{Ni}_{2} \mathrm{O}_{x}$ phase than in the $\mathrm{Ti}(\mathrm{C}, \mathrm{O})$ phase.

Author Contributions: F.Y., K.U., K.I., T.N. and M.N. conceived and designed the experiments; F.Y., Y.I., and S.K. (Suguru Kato and Sumio Kise) performed the experiments, analyzed the data, wrote original draft preparation; K.U., T.N. and M.N. wrote review and editing.

Funding: This work was partly supported by Grants-in-Aid for Scientific Research (A: No. 19H00829) from the Japanese Society for the Promotion of Science.

Acknowledgments: The authors are deeply grateful to Hisayoshi Yoneyama, Kenji Uruma and Yuji Oizumi of Furukawa Techno Materials for fabrication and testing of the samples.

Conflicts of Interest: The authors declare no conflicts of interest. 


\section{References}

1. Shabalovskaya, S.A. On the nature of the biocompatibility and on medical application of NiTi shape memory and superelastic alloys. Bio-Med. Mater. Eng. 1996, 6, 267-289.

2. Morgan, N.B. Medical shape memory alloy applications the market and its products. Mater. Sci. Eng. A 2004, 378, 16-23. [CrossRef]

3. Toro, A.; Zhou, F.; Wu, M.H.; Greertruyden, W.V.; Misiolek, W.Z. Characterization of non-metallic inclusion melting of NiTi shape memory alloys. J. Mater. Eng. Perform. 2009, 18, 448-485. [CrossRef]

4. Dehghanghadikolaei, A.; Ibrahim, H.; Amerinatanzi, A.; Hashemi, M.; Moghaddam, N.S.; Elahinia, M. Improving corrosion resistance of additively manufactured nickel-titanium biomedical devices by micro-arc oxidation process. J. Mater. Sci. 2019, 54, 7333-7355. [CrossRef]

5. Soria, S.R.; Callisaya, G.E.; Soul, H.; Claramonte, S.; Yawny, A. Fetting damage of Ni-rich ultrafine grained NiTi superelastic wires. J. Mech. Behav. Biomed. Mater. 2019, 90, 655-664. [CrossRef] [PubMed]

6. ASTM F2063-12: Standard Specification for Wrought Nickel-Titanium Shape Memory Alloys for Medical Devices and Surgical Implants; ASTM International: West Conshohocken, PA, USA, 2012.

7. Rahim, M.; Frenzel, J.; Frotscher, M.; Heuwer, B.; Hiebeler, J.; Eggeler, G. Bending rotaion HCF testing of pseudoelastic Ni-Ti shape memory alloys. Materialwissenschaft Werkstofftechnik 2013, 44, 633-640. [CrossRef]

8. Norwich, D.W.; Fasching, A. A study of the effect of diameter on the fatigue properties of NiTi wire. J. Mater. Eng. Perform. 2009, 18, 558-562. [CrossRef]

9. Rahim, M.; Frenzel, J.; Frotscher, M.; Pfetzing-Micklinch, J.; Steemúller, R.; Wohlschlőgel, M.; Mughrabi, H.; Eggeler, G. Impurity levels and fatigue lives of pseudoelastic NiTi shape memory alloys. Acta Mater. 2013, 61, 3667-3686. [CrossRef]

10. Sawaguchi, T.; Kaustrater, G.; Yawny, A.; Wagner, M.; Eggeler, G. Crack initiation and propagation in 50.9 at. pct Ni-Ti pseudoelastic shape-memory wires in bending-rotation fatigue. Matall. Mater. Trans. A 2003, 34A, 2847-2860. [CrossRef]

11. Schaffer, J.E.; Plumley, D.L. Fatigue performance of Nitinol round wire with varying cold work reductions. J. Mater. Eng. Perform. 2009, 18, 563-568. [CrossRef]

12. Ito, D.; Nishiwaki, N.; Ueda, K.; Narushima, T. Effect of Ba deoxidation on oxygen content in NiTi alloys and non-metallic inclusion. J. Mater. Sci. 2013, 48, 359-366. [CrossRef]

13. Hara, K.; Ueda, K.; Narushima, T.; Yamashita, F.; Ishikawa, K. Effect of light elements on fatigue properties of NiTi wires for designing biomedical stents. In Proceedings of the 24th International Conference on Processing and Fabrication of Advanced Materials, Osaka, Japan, 18-20 December 2015.

14. ASTM F2082-06: Standard Test Method for Determination of Transformation Temperature of Nickel-Titanium Shape Memory Alloy by Bend and Free Recovery; ASTM International: West Conshohocken, PA, USA, 2016.

15. Nurushima, T.; Suzuki, K.; Murakami, T.; Ouchi, C.; Iguchi, Y. Fatigue properties of stainless steel wire ropes for electrodes in functional electrical stimulation system. Mater. Trans. 2005, 46, 2083-2088. [CrossRef]

16. Yamashita, F.; Wakoh, M.; Ishikawa, K.; Shibata, H. In situ observation of nonmetallic inclusion formation in NiTi alloys. Mater. Trans. 2017, 12, 1729-1734. [CrossRef]

17. Jiang, B.; Xiao, J.; Huang, K.; Hou, J.; Jiao, S.; Zhu, H. Experimental and first-principles study of Ti-C-O system interplay of thermodynamic and structural properties. J. Am. Ceram. Soc. 2017, 100, 2253-2265. [CrossRef]

(C) 2019 by the authors. Licensee MDPI, Basel, Switzerland. This article is an open access article distributed under the terms and conditions of the Creative Commons Attribution (CC BY) license (http://creativecommons.org/licenses/by/4.0/). 